\title{
Article \\ Prospective Evaluation of Laparoscopic Sacrocolpopexy with Concomitant Laparoscopic-Assisted Total Vaginal Hysterectomy
}

\author{
Ivo Faehnle-Schiegg ${ }^{1, *}$, Janine Abgottspon ${ }^{2}$, Janine Frey ${ }^{1}$, Joerg Krebs ${ }^{3}$ and Corina Christmann-Schmid ${ }^{1}$ \\ 1 Departement of Urogynecology, Cantonal Hospital of Lucerne, CH-6000 Lucerne, Switzerland; \\ Janine.frey@luks.ch (J.F.); corina.christmann@luks.ch (C.C.-S.) \\ 2 Faculty of Medicine, University of Bern, CH-3010 Bern, Switzerland; abgottspon.janine@hotmail.com \\ 3 Clinical Trial Unit, Swiss Paraplegic Centre, CH-6207 Nottwil, Switzerland; joerg.krebs@paraplegie.ch \\ * Correspondence: ivo.faehnle@luks.ch
}

check for

updates

Citation: Faehnle-Schiegg, I.;

Abgottspon, J.; Frey, J.; Krebs, J.;

Christmann-Schmid, C. Prospective

Evaluation of Laparoscopic

Sacrocolpopexy with Concomitant

Laparoscopic-Assisted Total Vaginal

Hysterectomy. Surgeries 2022, 3, 4-10.

https://doi.org/10.3390/

surgeries3010002

Academic Editor: Zilvinas

Dambrauskas

Received: 6 November 2021

Accepted: 20 January 2022

Published: 24 January 2022

Publisher's Note: MDPI stays neutral with regard to jurisdictional claims in published maps and institutional affiliations.

Copyright: (c) 2022 by the authors. Licensee MDPI, Basel, Switzerland. This article is an open access article distributed under the terms and conditions of the Creative Commons Attribution (CC BY) license (https:// creativecommons.org/licenses/by/ $4.0 /)$.

\begin{abstract}
Background: Sacrocolpopexy (SCP) with subtotal hysterectomy (SH) is a standard procedure for the treatment of utero-vaginal prolapse. Several disadvantages are associated with the remaining cervix; therefor, SCP with total hysterectomy (TH) may be preferred. According to some publications, SCP with concomitant TH is associated with higher rates of mesh extrusion. Our hypothesis is that mesh extrusion at the apex can be avoided through prevention of thermal injury and through vaginal cuff suturing when performing the laparoscopic sacrocolpopexy combined with a laparoscopic-assisted vaginal total hysterectomy (LAVH). (2) Methods: This prospective cohort study was performed from 2016 until January 2019 including women with a utero-vaginal prolapse undergoing laparoscopic SCP with LAVH. The SCP was performed utilizing a non-absorbable polypropylene macroporous mesh (EndoGYNious ${ }^{\circledR}$ ). The primary outcome was the mesh extrusion rate after SCP with concomitant LAVH. The secondary outcome was the objective and functional outcome. (3) There were 50 women included in this prospective cohort. At follow up of 6-12 weeks postoperatively, no mesh extrusion was detected and objectified. Overall, all women showed excellent anatomical and functional outcome. The median time from surgery was 42 months. (4) Laparoscopic SCP with concomitant LAVH showed no increased risk of mesh extrusion and good objective and functional outcomes.
\end{abstract}

Keywords: hysterectomy; laparoscopy; mesh erosion; mesh extrusion; sacrocolpopexy

\section{Introduction}

With the steady decrease in hysterectomy rate over the last few decades [1], we will be undoubtedly ask how to repair apical and multicompartment prolapse in young, sexually and physically active women with a uterus.

Sacrocolpopexy (SCP) with subtotal hysterectomy $(\mathrm{SH})$ has become a standard surgical treatment option during the last decade for correction of pelvic organ prolapse (POP) in women with a uterus [2-6].

There are controversial discussions on retaining the cervix. Firstly, removing the uterus body and retaining the cervix ameliorates the mesh placement anteriorly along the apex down to the level of the bladder neck. Secondly, cautery-induced thermal injury to the vaginal cuff can be avoided and the risk of mesh infection and mesh extrusion can be reduced.

However, there are disadvantages leaving the cervix in situ. To remove the uterus body morcellation has to be performed with the possible risk of spillage [7]. Furthermore, regular Pap smears have to be taken and the effect on the stability and anterior vaginal support is not well understood. After all, in the case of a later cervical dysplasia, an eventual later removal of the cervix would be more challenging.

Apical and multicompartment defects can be treated with SCP with a high success rate $[8,9]$. It can be performed as an open or minimally invasive procedure $[3,6,10-13]$. In 
general, laparoscopic procedures are superior to their abdominal counterpart with regard to blood loss, postoperative pain, hospital stay and recovery time [14-16]. Various authors have shown a similar objective and subjective outcome after a laparoscopic/robotic-assisted approach compared to abdominal SCP [17].

To date, most women with utero-vaginal prolapse will undergo an SH concomitantly with an SCP. There is a wide range of rates of mesh extrusion reported; the overall rate seems to in the range from $0.7-3.6 \%[9,18,19]$. Some authors provide data suggesting that $\mathrm{TH}$ at the time of SCP is associated with higher mesh extrusion rates $[9,20,21]$ as well as general complications such as blood loss or surgical site infections [22].

Women with a history of cervical dysplasia, endometrium hyperplasia or abnormalities are not favorable for a SH. Some women explicitly want a total removal of the uterus to avoid future malignancies or regular visits for Pap smears.

The closure of the vaginal cuff seems to be an obvious risk factor for apical mesh extrusion. There is some evidence for higher rates of vaginal cuff dehiscence in laparoscopic hysterectomies than in the equivalent vaginal procedure. Rates of vaginal cuff dehiscence are reported for total laparoscopic hysterectomy in the range of $1.35-1.7 \%$ compared to laparoscopic-assisted total vaginal hysterectomy $(0.28 \%)$, total abdominal hysterectomy $(0.15 \%)$, and total vaginal hysterectomy (0.08\%) [23-25]. A double layer closure does not seem to provide an advantage. It is recommended that the sutures for mesh fixation are not placed on top of the colpotomy suture as this could lead to a mesh extrusion there [5]. Thus, higher rates of mesh extrusion with total hysterectomy (TH) are not consistently found in the literature. The reasons for higher rates in some studies are not explained in detail. Some data suggest that the monopolar cutting of the vagina as well as the laparoscopic suturing technique are linked to this complication [26,27].

We postulate that mesh extrusion in SCP with concomitant TH is due to the same causes and related to insufficient vaginal cuff closure and thermal tissue damage.

In order to decrease these risk factors when performing TH with concomitant SCP, we chose an approach of laparoscopic-assisted vaginal hysterectomy (LAVH) with the vaginal removal of the uterus after laparoscopic preparation without monopolar cutting and with a continuous vaginal suturing of the vaginal cuff.

The aim of this study was to evaluate if mesh extrusion can be prevented using this surgical technique in SCP with TH and to assess the subjective and objective outcome postoperatively.

\section{Materials and Methods}

In this prospective cohort study, we identified and included 50 women who did not meet the criteria of a subtotal hysterectomy at the time of SCP from 2016 to 2019 at our tertiary referral hospital at the department for Urogynecology. The study was approved by the Local Ethics Committee (EKNZ 01676).

All women met the primary criteria for an SCP for the repair of an apical or multicompartment prolapse with a concurrent indication for a total hysterectomy, including abnormal uterine bleeding, dysmenorrhea, dysplasia or fibroids or wish of total removal of the uterus. The exclusion criterion was evidence or suspicion of malignancy.

Pre- and six to twelve weeks postoperatively, all women had a uroflowmetry, evaluation and determination of post-void residual volume (PVR) according to ICS/IUGA [28], and a cough test with a full bladder with and without prolapse reduction [5].

Transvaginal ultrasound was performed to detect abnormal endometrial thickness or pathologies.

A Pap smear was taken if no current result was available according to Swiss guidelines [29].

For the LAVH, the laparoscopic standard procedure for the laparoscopic hysterectomy containing the preparation of the uterus down to the uterine vessels was performed. Consecutively, the vesico-vaginal space was dissected down to the level of the bladder neck, and the recto-vaginal space was dissected down to the perineal body. We used the 
Schaer uterine manipulator by Storz. The LAVH was completed vaginally without the use of any monopolar electricity and the vaginal cuff was closed using continuous suturing with Vicryl 2-0. The subsequent SCP was performed equally to the procedure with SH using the EndoGYNious ${ }^{\circledR}$ mesh for fixation to the vagina anterior, posterior and apical with PDS 3-0 multiple single-knot sutures and ProTack ${ }^{\circledR}$ titanium screws for the suspension of the mesh at the level of the sacral promontory [30].

The primary outcome was to evaluate the mesh extrusion rate. The secondary outcome measures were subjective and objective cure rates.

The objective outcome measures were documented with POP-Q values pre- and six to twelve weeks postoperatively [31].

The subjective outcome was evaluated utilizing the validated German pelvic floor questionnaire (GPFQ) to record subjective outcome findings pre- and six to twelve weeks postoperatively [32]. We evaluated the global question ("How much of a bother is this to you?") for each of the four domains (bladder function, bowel function, prolapse, sexual function). The following answer options were available: 0 -not applicable, 1 -not at all bothersome, 2-slightly bothersome, 3-moderatley bothersome, 4-greatly bothersome. The answers were categorized into "not bothersome" (0-not applicable, 1-not at all bothersome) and "bothersome" (1-slightly bothersome to 4-greatly bothersome).

Proportions and 95\% confidence intervals (CI) using the Clopper-Pearson exact binomial method as well as the median and the lower and upper quartiles were calculated. The differences in the proportions between the time points were tested using the Chi-square test. The differences in the ordinal data between the time points were tested using the Wilcoxon signed-rank test. The statistical analyses were performed using the $\mathrm{R}$ software environment (version 4.0.2, Copyright 2020, The R Foundation for Statistical Computing). A $p$-value of $\leq 0.05$ was considered significant.

\section{Results}

Between 2016 and 2019, we performed TH and SCP in 50 women, of whom all were included in this cohort. Baseline characteristics are summarized in Table 1. All patients were seen for follow-up at 6-12 weeks postoperatively. For our cohort, the median time from surgery was 42 months ( 3 years, 6 months).

Table 1. Patient characteristics.

\begin{tabular}{cc}
\hline Demographics $(\boldsymbol{n = 5 0 )}$ & \\
\hline Mean age (years) & $58($ SD 9.4$)$ \\
Menopause & $64 \%(32 / 50)$ \\
Parity (range) & $2.1(0-5)$ \\
Previous pelvic floor surgery & 0 \\
Previous anti-incontinence procedure & $1(2 \%)$ \\
Concomitant surgery & $4(8 \%)$ \\
TVT sling & $1(2 \%)$ \\
Other (umbilical hernia repair) & \\
\hline
\end{tabular}

We had no cases of mesh extrusion and none of the women had a severe adverse event such as blood transfusion or viscus injury.

The subjective outcome data from the GPFQ are shown in Table 2. There is a significant $(p<0.0001)$ improvement in all four domains of the questionnaire (bladder function, bowel function, pelvic organ prolapse and sexual function). There is a higher rate of resolutions of symptoms for the domains of prolapse, bowel function and sexual function compared to bladder function. 
Table 2. Subjective outcome according to GPFQ

\begin{tabular}{ccccc}
\hline Variable & Time Point & No & \% (95\% CI) & $p$ \\
\hline Bladder function & Pre-op & 39 & $78(64.0-88.5)$ & 0.0002 \\
disorder & Post-op & 21 & $42(28.2-56.8)$ & $<0.0001$ \\
\hline Bowel function & Pre-op & 24 & $48(33.7-62.6)$ & \\
disorder & Post-op & 6 & $12(4.5-24.3)$ & $<0.0001$ \\
\hline Pelvic organ & Pre-op & 47 & $94(83.5-98.7)$ & \\
prolapse & Post-op & 3 & $6(1.3-16.5)$ & $<0.0001$ \\
\hline Sexual function & Pre-op & 22 & $44(30.0-58.7)$ & \\
disorder & Post-op & 1 & $2(0.1-10.6)$ & \\
\hline
\end{tabular}

The objective outcomes for values Ba, Bp and C/D are shown in Table 3. A complete repair of the prolapse was achieved for all three compartments.

Table 3. POP-Q preoperative vs. postoperative.

\begin{tabular}{cccc}
\hline POP-Q Values $(\boldsymbol{n}=\mathbf{5 0})$ & Preoperative & Postoperative & $p$ \\
\hline Ba median $(\mathrm{Q} 25 / \mathrm{Q} 75)$ & $+1(0 /+2)$ & $-3(-3 /-2)$ & $<0.0001$ \\
C/D median Q25/Q75) & $-2(-4.25 / 2)$ & $-10(-11 /-8.75)$ & $<0.0001$ \\
Bp median Q25/Q75) & $-1(-2 / 0)$ & $-3(-3 /-2.75)$ & $<0.0001$ \\
\hline
\end{tabular}

As for the surgical technique, SCP could be very well combined with an LAVH. We experienced that, in most cases, an additional preparation of the anterior vaginal wall was necessary after closure of the vaginal cuff in order to be able to properly place the mesh. This seems to be a particular situation differing from the technique for the SCP with SH. Indeed, no additional difficulties or adverse events were associated with this additional step. The performance of this surgical technique was feasible without additional time needed. Our median operation time was $131 \mathrm{~min}$ (ranging from 90 to $220 \mathrm{~min}$ ). On the one hand, it took some extra time to change the position intraoperatively from laparoscopic to vaginal and back, while on the other hand, we saved time as the uterus could be removed vaginally and no morcellation was needed.

\section{Discussion}

Our study demonstrates that women undergoing SCP with a concomitant LAVH for utero-vaginal prolapse have excellent objective and subjective outcomes.

From a surgical point of view, there are some differences between the two options of $\mathrm{SH}$ or TH with SCP. We did not need more OR time because the extra time used for the LAVH was spared by the lack of need for morcellation of the uterus. A particular challenge was the dissection of the vesico-vaginal space after the closure of the vaginal cuff, although the plane was pre-prepared as to the surgical protocol of SH with an SCP. The closure seems to partially distort the anterior space. The suture often leads to an asymmetric anatomical situation along the anterior vaginal wall. Before the mesh can be placed anteriorly, the surgeon has to verify the correct preparation down to the level of the bladder neck. The procedure with the fixation of the mesh can then be completed as previously described [30]. There was no difference in dissecting the recto-vaginal space posteriorly in the procedure with TH compared to SH.

We state that our technique of LAVH without the use of monopolar power for removal of the uterus and vaginal continuous suturing for closure of the vaginal cuff is a safe option in order to avoid vaginal cuff dehiscence, which could result in vaginal apical mesh extrusion. These data are in contrast to earlier data for laparoscopic SCP with concurrent $\mathrm{TH}[33]$.

For the patient, it can be advantageous if the additional option of a TH is present if an SCP is planned and therefore no two-stage surgery is needed. In our opinion, it is 
important to offer this treatment option of SCP with concomitant TH especially to young, active and sexually active women with utero-vaginal prolapse. The alternative to this combined procedure of SCP with TH compared to either vaginal hysterectomy, vaginal anterior/posterior repair with high uterosacral suspension (HUSLS) or a sacro-spinous fixation (SSF) is associated with a lower objective success rate and higher dyspareunia rate for SSF [6,34]. The subjective outcome for sexual function was high in the LAVH; thus, we cannot determine a disadvantage in this regard. This finding is consistent with improved sexual activity and quality after TH with SCP [35].

The major limitations of this study are the rather small number of cases and the duration of follow-up. Although we offer both options (SH vs. TH) to our patients, we perform more SCP with $\mathrm{SH}$ than with $\mathrm{TH}$ if there is no indication for $\mathrm{TH}$. Considerations for this are that the remaining cervix is well suited for mesh fixation and the fact that no vaginal suturing and consequent scarring is possible.

Concerning the follow-up, we experienced a very low number of mesh protrusions. We are the tertiary referral hospital for urogynecology for the whole region of central Switzerland; therefore, we probably see almost all cases of long-term complications in patients who were operated on in our clinic.

In the literature, the rate of mesh extrusion (erosion) is reported to be in the range of $0.7-3.6 \%$ in SCP with SH [9]. Consequently, we can conclude that our mesh protrusion rate in this cohort is not higher than in SCP with SH. This suits the fact that the option of $\mathrm{TH}$ at the time of SCP is increasingly discussed. In contrast to previous publications, there are several more recent studies indicating no disadvantages for this technique. To reinforce this finding as a future perspective, it will be essential to study larger patient groups and have a longer follow-up. We plan to continue to perform this technique if indicated and to follow the study participants in the coming years.

Overall, our findings indicate that a deliberate technique for closure of the vaginal cuff allows SCP with combined TH to be performed without implication on feasibility, objective and subjective success rate and vaginal mesh extrusion also in elderly women. This option seems to be a safe option for women with utero-vaginal prolapse and an indication for $\mathrm{TH}$.

Author Contributions: Investigation, I.F.-S. and J.F.; data curation I.F.-S. and J.A.; formal analysis, J.K.; conceptualization, I.F.-S. and C.C.-S.; writhing-review and editing, I.F.-S., C.C.-S. and J.K.; supervision, C.C.-S. All authors have read and agreed to the published version of the manuscript.

Funding: This research received no external funding.

Institutional Review Board Statement: The study was conducted according to the guidelines of the Declaration of Helsinki and approved by the local Ethics Committee (EKNZ 01676 (2016)).

Informed Consent Statement: Informed consent was obtained from all subjects involved in the study.

Data Availability Statement: The data presented in this study are available on request from the corresponding author. The data are not publicly available due to privacy.

Conflicts of Interest: The authors declare no conflict of interest.

\section{References}

1. Edler, K.; Tamussino, K.; Fülöp, G.; Reinstadler, E.; Neunteufel, W.; Reif, P.; Laky, R.; Aigmüller, T. Rates and Routes of Hysterectomy for Benign Indications in Austria 2002-2014. Geburtshilfe Und Frauenheilkd. 2017, 77, 482-486. [CrossRef] [PubMed]

2. Manodoro, S.; Werbrouck, E.; Veldman, J.; Haest, K.; Corona, R.; Claerhout, F.; Coremans, G.; De Ridder, D.; Spelzini, F.; Deprest, J. Laparoscopic Sacrocolpopexy. Facts Views Vis. Obgyn. 2011, 3, 151-158. [PubMed]

3. Parkes, I.L.; Shveiky, D. Sacrocolpopexy for Treatment of Vaginal Apical Prolapse: Evidence-Based Surgery. J. Minim. Invasive Gynecol. 2014, 21, 546-557. [CrossRef] [PubMed]

4. Coolen, A.-L.W.M.; van IJsselmuiden, M.N.; van Oudheusden, A.M.J.; Veen, J.; van Eijndhoven, H.W.F.; Mol, B.W.J.; Roovers, J.P.; Bongers, M.Y. Laparoscopic Sacrocolpopexy versus Vaginal Sacrospinous Fixation for Vaginal Vault Prolapse, a Randomized Controlled Trial: SALTO-2 Trial, Study Protocol. BMC Women's Health 2017, 17, 52. [CrossRef]

5. Moore, R.D.; Miklos, J.R. Laparoscopic Sacral Colpopexy. Surg. Technol. Int. 2008, 17, 195-202. 
6. Maher, C.; Feiner, B.; Baessler, K.; Christmann-Schmid, C.; Haya, N.; Brown, J. Surgery for Women with Apical Vaginal Prolapse. Cochrane Database Syst. Rev. 2016, 2016, 1-191. [CrossRef]

7. Günthert, A.R.; Christmann, C.; Kostov, P.; Mueller, M.D. Safe Vaginal Uterine Morcellation Following Total Laparoscopic Hysterectomy. Am. J. Obstet. Gynecol. 2015, 212, 546.e1-546.e4. [CrossRef]

8. Sarlos, D.; Kots, L.; Ryu, G.; Schaer, G. Long-Term Follow-up of Laparoscopic Sacrocolpopexy. Int. Urogynecol. J. 2014, 25, 1207-1212. [CrossRef]

9. Stepanian, A.A.; Miklos, J.R.; Moore, R.D.; Mattox, T.F. Risk of Mesh Extrusion and Other Mesh-Related Complications After Laparoscopic Sacral Colpopexy with or without Concurrent Laparoscopic-Assisted Vaginal Hysterectomy: Experience of 402 Patients. J. Minim. Invasive Gynecol. 2008, 15, 188-196. [CrossRef]

10. Khan, A.; Alperin, M.; Wu, N.; Clemens, J.Q.; Dubina, E.; Pashos, C.L.; Anger, J.T. Comparative Outcomes of Open versus Laparoscopic Sacrocolpopexy among Medicare Beneficiaries. Int. Urogynecol. J. 2013, 24, 1883-1891. [CrossRef]

11. Coolen, A.L.W.M.; Bui, B.N.; Dietz, V.; Wang, R.; van Montfoort, A.P.A.; Mol, B.W.J.; Roovers, J.P.W.R.; Bongers, M.Y. The Treatment of Post-Hysterectomy Vaginal Vault Prolapse: A Systematic Review and Meta-Analysis. Int. Urogynecol. J. 2017, 28, 1767-1783. [CrossRef] [PubMed]

12. De Gouveia De Sa, M.; Claydon, L.S.; Whitlow, B.; Dolcet Artahona, M.A. Laparoscopic versus Open Sacrocolpopexy for Treatment of Prolapse of the Apical Segment of the Vagina: A Systematic Review and Meta-Analysis. Int. Urogynecol. J. 2016, 27, 3-17. [CrossRef] [PubMed]

13. Costantini, E.; Mearini, L.; Lazzeri, M.; Bini, V.; Nunzi, E.; di Biase, M.; Porena, M. Laparoscopic Versus Abdominal Sacrocolpopexy: A Randomized, Controlled Trial. J. Urol. 2016, 196, 159-165. [CrossRef] [PubMed]

14. Coolen, A.W.M.; van Oudheusden, A.M.J.; van Eijndhoven, H.W.F.; van der Heijden, T.P.F.M.; Stokmans, R.A.; Mol, B.W.J.; Bongers, M.Y. A Comparison of Complications between Open Abdominal Sacrocolpopexy and Laparoscopic Sacrocolpopexy for the Treatment of Vault Prolapse. Obstet. Gynecol. Int. 2013, 2013, 528636. [CrossRef] [PubMed]

15. Coolen, A.L.W.M.; van Oudheusden, A.M.J.; Mol, B.W.J.; van Eijndhoven, H.W.F.; Roovers, J.P.W.R.; Bongers, M.Y. Laparoscopic Sacrocolpopexy Compared with Open Abdominal Sacrocolpopexy for Vault Prolapse Repair: A Randomised Controlled Trial. Int. Urogynecol. J. 2017, 28, 1469-1479. [CrossRef] [PubMed]

16. Freeman, R.M.; Pantazis, K.; Thomson, A.; Frappell, J.; Bombieri, L.; Moran, P.; Slack, M.; Scott, P.; Waterfield, M. A Randomised Controlled Trial of Abdominal versus Laparoscopic Sacrocolpopexy for the Treatment of Post-Hysterectomy Vaginal Vault Prolapse: LAS Study. Int. Urogynecol. J. 2013, 24, 377-384. [CrossRef]

17. Aarts, J.W.; Nieboer, T.E.; Johnson, N.; Tavender, E.; Garry, R.; Mol, B.W.J.; Kluivers, K.B. Surgical Approach to Hysterectomy for Benign Gynaecological Disease. Cochrane Database Syst. Rev. 2015, 2015, 1-214. [CrossRef]

18. Nygaard, I.E.; McCreery, R.; Brubaker, L.; Connolly, A.; Cundiff, G.; Weber, A.M.; Zyczynski, H. Abdominal Sacrocolpopexy: A Comprehensive Review: Obstet. Gynecol. 2004, 104, 805-823. [CrossRef]

19. Baines, G.; Price, N.; Jefferis, H.; Cartwright, R.; Jackson, S.R. Mesh-Related Complications of Laparoscopic Sacrocolpopexy. Int Urogynecol. J. 2019, 30, 1475-1481. [CrossRef]

20. Nosti, P.A.; Lowman, J.K.; Zollinger, T.W.; Hale, D.S.; Woodman, P.J. Risk of Mesh Erosion after Abdominal Sacral Colpoperineopexy with Concomitant Hysterectomy. Am. J. Obstet. Gynecol. 2009, 201, 541.e1-541.e4. [CrossRef]

21. Wu, J.M.; Wells, E.C.; Hundley, A.F.; Connolly, A.; Williams, K.S.; Visco, A.G. Mesh Erosion in Abdominal Sacral Colpopexy with and without Concomitant Hysterectomy. Am. J. Obstet. Gynecol. 2006, 194, 1418-1422. [CrossRef] [PubMed]

22. Winkelman, W.D.; Modest, A.M.; Richardson, M.L. The Surgical Approach to Abdominal Sacrocolpopexy and Concurrent Hysterectomy: Trends for the Past Decade. Female Pelvic. Med. Reconstr. Surg. 2021, 27, e196-e201. [CrossRef] [PubMed]

23. Hur, H.C.; Donnellan, N.; Mansuria, S.; Barber, R.E.; Guido, R.; Lee, T. Vaginal Cuff Dehiscence after Different Modes of Hysterectomy. Obstet. Gynecol. 2011, 118, 794-801. [CrossRef]

24. Sandberg, E.M.; Twijnstra, A.R.H.; Driessen, S.R.C.; Jansen, F.W. Total Laparoscopic Hysterectomy Versus Vaginal Hysterectomy: A Systematic Review and Meta-Analysis. J. Minim. Invasive Gynecol. 2017, 24, 206-217e22. [CrossRef]

25. Clarke-Pearson, D.L.; Geller, E.J. Complications of Hysterectomy. Obstet. Gynecol. 2013, 121, 654-673. [CrossRef]

26. Cronin, B.; Sung, V.W.; Matteson, K.A. Vaginal Cuff Dehiscence: Risk Factors and Management. Am. J. Obstet. Gynecol. 2012, 206, 284-288. [CrossRef]

27. Lawlor, M.L.; Rao, R.; Manahan, K.J.; Geisler, J.P. Electrosurgical Settings and Vaginal Cuff Complications. JSLS J. Soc. Laparoendosc. Surg. 2015, 19, e201500088. [CrossRef]

28. Haylen, B.T.; de Ridder, D.; Freeman, R.M.; Swift, S.E.; Berghmans, B.; Lee, J.; Monga, A.; Petri, E.; Rizk, D.E.; Sand, P.K.; et al. An International Urogynecological Association (IUGA)/International Continence Society (ICS) Joint Report on the Terminology for Female Pelvic Floor Dysfunction. Neurourol. Urodyn. 2009, 29, 4-20. [CrossRef]

29. Gerber, S.; Heinzl, S.; Canonica, H.; Fehr, H.; Frey Tirri, B.; Mueller, M.; Obwegeser, J.; Seydoux, J.; Wight, E. Update Des Screenings Fuer Gebärmutterhalskrebs Und Follow-up Mittels Kolposkopie (Expertenbrief No 40). Schweiz. Z. Fur Gynakol. 2012, $17,28-29$.

30. Maher, C.F.; Feiner, B.; DeCuyper, E.M.; Nichlos, C.J.; Hickey, K.V.; O’Rourke, P. Laparoscopic Sacral Colpopexy versus Total Vaginal Mesh for Vaginal Vault Prolapse: A Randomized Trial. Am. J. Obstet. Gynecol. 2011, 204, 360.e1-360.e7. [CrossRef]

31. Bump, R.C.; Mattiasson, A.; Bø, K.; Brubaker, L.P.; DeLancey, J.O.L.; Klarskov, P.; Shull, B.L.; Smith, A.R.B. The Standardization of Terminology of Female Pelvic Organ Prolapse and Pelvic Floor Dysfunction. Am. J. Obstet. Gynecol. 1996, 175, 10-17. [CrossRef] 
32. Baessler, K.; Kempkensteffen, C. Validierung Eines Umfassenden Beckenboden-Fragebogens Für Klinik, Praxis Und Forschung. Gynaekol Geburtshilfliche Rundsch 2009, 49, 299-307. [CrossRef]

33. Bensinger, G.; Lind, L.; Lesser, M.; Guess, M.; Winkler, H.A. Abdominal Sacral Suspensions: Analysis of Complications Using Permanent Mesh. Am. J. Obstet. Gynecol. 2005, 193, 2094-2098. [CrossRef]

34. Rondini, C.; Braun, H.; Alvarez, J.; Urzúa, M.J.; Villegas, R.; Wenzel, C.; Descouvieres, C. High Uterosacral Vault Suspension vs Sacrocolpopexy for Treating Apical Defects: A Randomized Controlled Trial with Twelve Months Follow-Up. Int. Urogynecol. J. 2015, 26, 1131-1138. [CrossRef]

35. Geller, E.J.; Bretschneider, C.E.; Wu, J.M.; Kenton, K.; Matthews, C.A. Sexual Function after Minimally Invasive Total Hysterectomy and Sacrocolpopexy. J. Minim. Invasive Gynecol. 2021, 28, 1603-1609. [CrossRef] 